\title{
Flow Field Investigations and Aerodynamic Characteristics of Artillery Projectile
}

\author{
M.E. Wessam \\ Key Laboratory of Transient Physics \\ Nanjing University of Science \& Technology \\ Nanjing, China
}

\begin{abstract}
This paper describes a computational study to determine the aerodynamic coefficients at subsonic and supersonic speeds using an unstructured flow solver. The paper presents results of investigation of a flow over $155 \mathrm{~mm}$ artillery projectile M107 and the performance of the ANSYS FLUENT computational code. The flow around projectile was solved as 3-D unsteady compressible flow.
\end{abstract}

Keywords-artillery projectile; aerodynamic coefficients; CFD;ANSYS FLUENT

\section{INTRODUCTION}

Flow field over a projectile presents turbulent boundary layers, whose separation is a usual phenomena and a large turbulent wake formed at the bottom of the object. In ballistic aerodynamics, prevention or control of the separation of the boundary layer is one of the most important aims, as well as an appropriate ogive design $[1,2]$. In this work, the computational fluid dynamics (CFD) is applied to determine the aerodynamic coefficients by using ANSYS FLUENT14.5 which takes the meshed computational domain from a pre-processor program called ANSYS ICEM-CFD in which the computational domain is generated and meshed into cells. The implicit segregated structured grid solver was used in these investigations. Second order upwind discritization was used for the flow variables and turbulent viscosity equations; furthermore a comparison with available experimental data was performed. The aim of the present work is to determine the aerodynamic coefficients of a projectile as well as flow field investigation around the artillery projectile.

\section{COMPUTATIONAL FLUID DYNAMICS}

\section{A. Model Geometry}

Fig. 1 shows the solid model and main dimensions of the test projectile. The full scale $155 \mathrm{~mm}$ artillery projectile was generated in INVENTOR software and modeled in CFD simulations, in order to determine static aerodynamic coefficients. All dimensions are in calibers and reference diameter is $154.7 \mathrm{~mm}$ [3].

\author{
Z.H. Chen
Key Laboratory of Transient Physics
jing University of Science \& Technology \\ Z.H. Chen
Key Laboratory of Transient Physics
jing University of Science \& Technology \\ Z.H. Chen
Key Laboratory of Transient Physics
Nanjing University of Science \& Technology \\ Nanjing, China
}

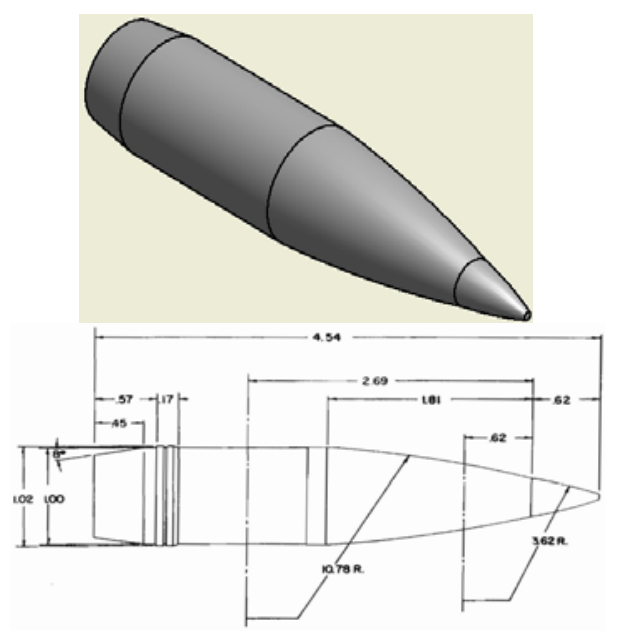

FIGURE I.

$$
\begin{aligned}
& \text { TEST PROJECTILE SOLID MODEL AND MAIN } \\
& \text { DIMENSIONS }
\end{aligned}
$$

\section{B. Grid Generation}

The grids for the geometry investigated were obtained from ANSYS ICEM-CFD software as the numerical grids had been previously constructed. Quadrilateral cells were used in domain. The projectile contained hexahedral cells. The total number of mesh equals 346352 cells. The computational domain was extended to be 7 times diameter far from projectile base, 3 times diameter around the projectile, and 1 time diameter far from projectile nose as shown in fig. 2 .

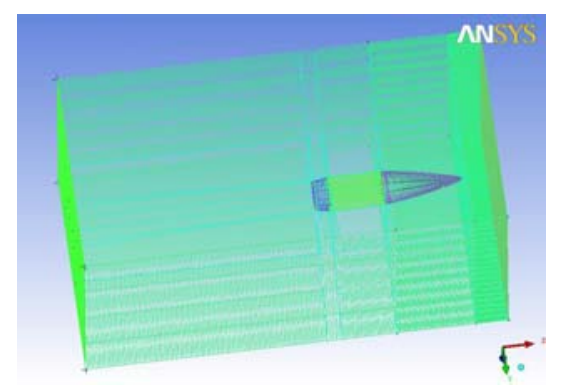

FIGURE II. DOMAIN 


\section{Solving Methodology}

CFD is applied to determine the aerodynamic coefficients by using ANSYS FLUENT. The governing equation in this work is the full Navier-Stokes equation. The Turbulence model was one of the most simple and good agreement one equation model which is the Spalart-Allmaras turbulent model. The model solves one transport equation for a quantity that is a modified form of the turbulent kinematics' viscosity and has provided better agreement with available experimental data. The convective term is approximated by second order Roe-FDS scheme. The second order central difference scheme is applied to pursuing numerical approximation of the viscous term. Runge Kutta method was applied to step on time. For Spalart-Allmaras model, you should check that $y^{+}$of the wall-adjacent cells is either very small (on the order of $y^{+}=1$ ), or approximately 30 or greater. The values of $y^{+}$are dependent on the resolution of the mesh and the Reynolds number of the flow, and are defined only in wall-adjacent cells. The value of $y^{+}$in the wall-adjacent cells dictates how wall shear stress is calculated.

The equation for $y^{+}$is as follows:

$$
\mathrm{y}^{+}=\frac{\mathrm{y}}{\mu} \sqrt{\rho \tau_{\omega}}
$$

where $y$ is the distance from the wall to the cell center, $\mu$ is the molecular viscosity, $\rho$ is the density of the air, and $\tau_{\omega}$ is the wall shear stress. The drag coefficient can be better predicted if the $y^{+}$value is kept in the range of 30-100 as shown in fig. 3 .

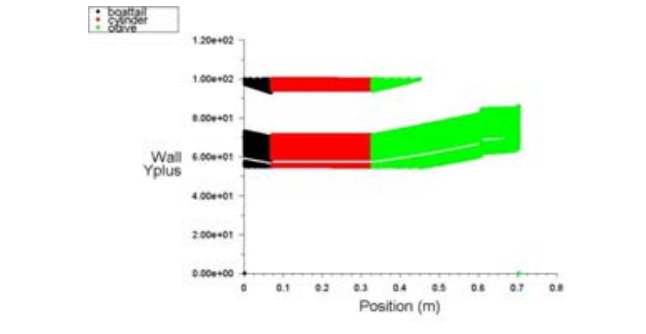

FIGURE III. $\quad$ XY PLOT OF Y+ DISTRIBUTION

\section{Boundary Conditions}

The far field boundary is set to pressure far field density-based. This boundary condition is a characteristic type that allows the solver to determine the conditions at the far field boundary and either implicitly sets the boundary condition to free stream conditions. Free stream pressure and temperature are set to $1 \mathrm{~atm}$ and $300 \mathrm{~K}$, respectively. Density is then calculated from the perfect gas assumption. Angles of attack are taken as $\left(\alpha=0^{\circ}, 4^{\circ}, 8^{\circ}\right.$ and $\left.12^{\circ}\right)$ and Mach numbers are taken as $(\mathrm{M}=0.6,0.9,1.2,1.5,2.0$, and 2.5$)$.

\section{RESUlTS AND DisCUSSION}

\section{A. Contours of Static Pressure and Mach Number Distribution}

Fig. 4 shows the symmetric distribution of pressure over the projectile body due to zero angle of attack; furthermore the shock wave transforms from bow shocks to oblique shocks and closer to surface with increasing of Mach number. Also, Mach number distribution is symmetric over projectile surface and the shock waves become stronger with increasing of Mach number (fig. 5).

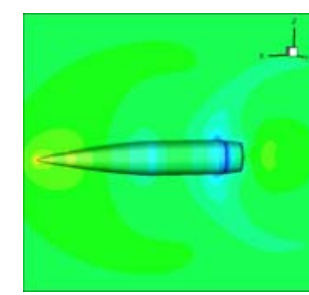

(a) $\mathrm{M}=0.6$

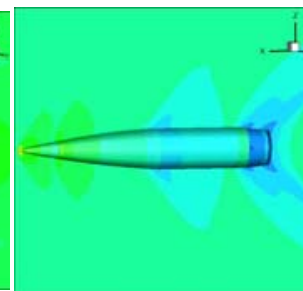

(b) $\mathrm{M}=1.2$

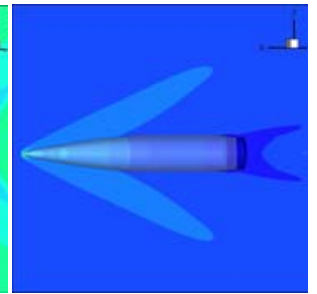

(c) $\mathrm{M}=2.5$
FIGURE IV. CONTOURS OF STATIC PRESSURE FOR DIFFERENT MACH NUMBERS AT A $=0^{\circ}$

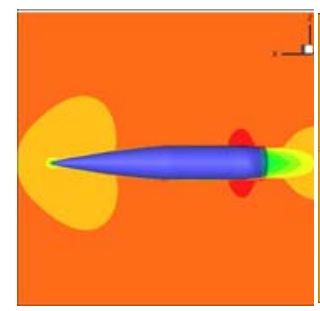

(a) $\mathrm{M}=0.6$

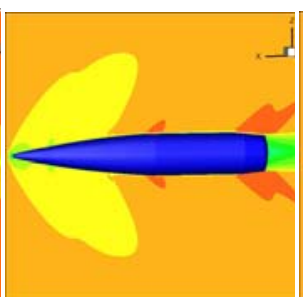

(b) $\mathrm{M}=1.2$

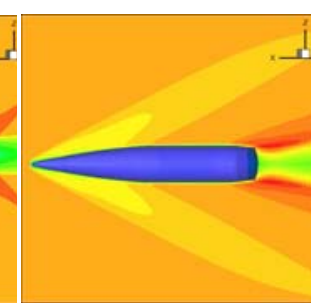

(c) $\mathrm{M}=2.5$
FIGURE V. MACH NUMBER DISTRIBUTION FOR DIFFERENT MACH NUMBERS AT A $=0^{\circ}$

\section{B. Aerodynamic Coefficients}

Static aerodynamic coefficient for studied projectile are calculated using ANSYS FLUENT14.5. The drag force convergence history with different Mach numbers at zero angle of attack is given in fig. 6

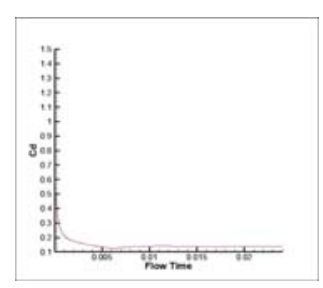

(a) $\mathrm{M}=0.9$

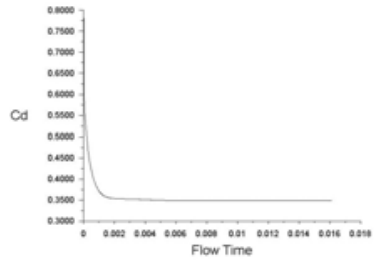

(b) $\mathrm{M}=1.5$

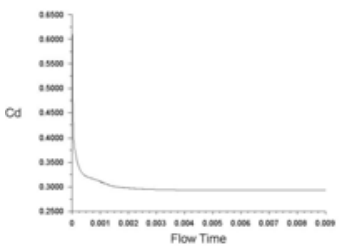

(c) $\mathrm{M}=2$

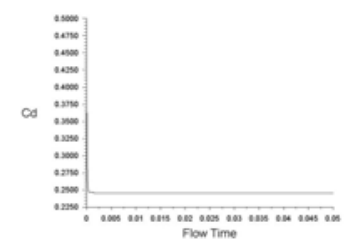

(d) $M=2.5$
FIGURE VI. DRAG COEFFICIENT CONVERGENCE HISTORIES AT ZERO ANGLE OF ATTACK 
Fig. 7 shows the lift convergence history at different angles of attack. The figure shows that the lift force coefficient increases as angle of attack increases. The lift force coefficient was calculated as $\left(C_{L_{\alpha}}=\frac{\partial C_{L}}{\partial \alpha}\right)$.

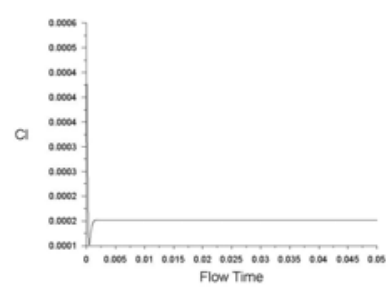

(a) $\alpha=0^{\circ}$

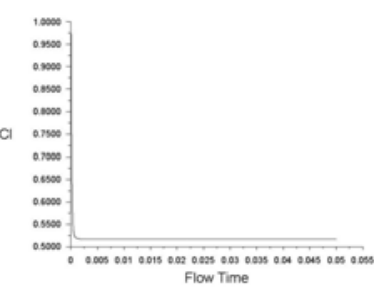

(b) $\alpha=12^{\circ}$
FIGURE VII. LIFT COEFFICIENT CONVERGENCE HISTORIES AT DIFFERENT ANGLES OF ATTACK

Fig. 8 shows the moment convergence history at different angles of attack. The figure shows that the moment force coefficient increases as angle of attack increases. Overturning moment coefficient was calculated as $\left(\mathrm{C}_{\mathrm{M}_{\alpha}}=\frac{\partial C_{M}}{\partial \alpha}\right)$. Table 1 shows the results of computation of aerodynamic coefficients as a function of Mach number.

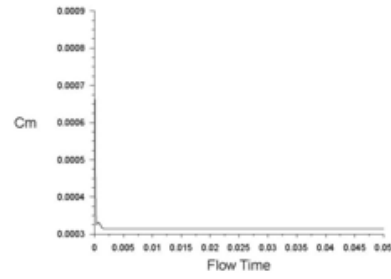

(a) $\alpha=0^{\circ}$

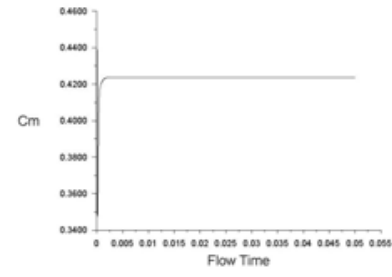

(b) $\alpha=12^{\circ}$
FIGURE VIII. MOMENT COEFFICIENT CONVERGENCE HISTORIES AT DIFFERENT ANGLES OF ATTACK

TABLE I. AERodynamic CoefFicients For the TeSt ProjeCtile.

\begin{tabular}{|c|c|c|c|c|c|}
\hline $\mathbf{M}$ & $\mathbf{C}_{\mathbf{D}}$ & $\boldsymbol{C}_{\boldsymbol{L}_{\alpha}}$ & $\mathbf{C}_{\mathbf{M}_{\boldsymbol{\alpha}}}$ & $\boldsymbol{C}_{\boldsymbol{N}_{\boldsymbol{p} \alpha}}$ & $\mathbf{C}_{\mathbf{l}_{p}}$ \\
\hline \hline 0.010 & 0.1455 & 1.6940 & 3.1000 & -0.7670 & -0.0230 \\
\hline 0.400 & 0.1455 & 1.6940 & 3.1371 & -0.7670 & -0.0230 \\
\hline 0.600 & 0.1455 & 1.6940 & 3.1870 & -0.7670 & -0.0230 \\
\hline 0.700 & 0.1425 & 1.7110 & 3.3727 & -0.7903 & -0.0226 \\
\hline 0.800 & 0.1396 & 1.7280 & 3.6856 & -0.8337 & -0.0217 \\
\hline 0.900 & 0.1366 & 1.7450 & 3.8510 & -0.8570 & -0.0210 \\
\hline 0.950 & 0.1773 & 1.8393 & 3.8355 & -0.8503 & -0.0208 \\
\hline 0.975 & 0.1977 & 1.8865 & 3.8179 & -0.8429 & -0.0207 \\
\hline 1.000 & 0.2181 & 1.9337 & 3.7951 & -0.8337 & -0.0205 \\
\hline 1.025 & 0.2384 & 1.9080 & 3.7683 & -0.8231 & -0.0204 \\
\hline 1.050 & 0.2588 & 2.0280 & 3.7386 & -0.8120 & -0.0203 \\
\hline 1.100 & 0.2995 & 2.1223 & 3.6750 & -0.7903 & -0.0202 \\
\hline 1.200 & 0.3810 & 2.3110 & 3.5620 & -0.7670 & -0.0200 \\
\hline 1.350 & 0.3646 & 2.3275 & 3.4192 & -0.7670 & -0.0200 \\
\hline 1.500 & 0.3481 & 2.3440 & 3.3310 & -0.7670 & -0.0200 \\
\hline 1.750 & 0.3206 & 2.3590 & 3.3125 & -0.7670 & -0.0205 \\
\hline 2.000 & 0.2931 & 2.3740 & 3.2990 & -0.7670 & -0.0210 \\
\hline 2.500 & 0.2452 & 2.5230 & 3.2300 & -0.7670 & -0.0200 \\
\hline
\end{tabular}

\section{CFD Validation}

In Exterior Ballistics, the specialty related to projectile flight studies, the drag coefficient curve takes a fundamental role for different applications, such as the generation of firing tables. These curves can be obtained also from tests inside wind tunnels or theoretical calculus. In the first case, the interferences between the projectile or its model and the tunnel walls affect the precision of results; in the second, the hypothesis adopted could move the results away from the real behavior. Because of the limitations of the methods mentioned before, a different way for the making up of these curves is the identification of the aerodynamic properties of an object from flight test over a real specimen. Fig. 6 shows the Comparison between the drag coefficient curves obtained by the CFD simulations for $0^{\circ}$ angle of attack and the drag curves obtained from [3]. From Figure 9, the drag coefficients show an excellent agreement with the experimental data.

\section{CONCLUSION}

3-D unsteady flow CFD simulation over a spinning projectile model, regardless the spinning motion of projectile was performed at subsonic, transonic and supersonic Mach numbers with various angles of attack using a commercial CFD code called (ANSYS FLUENT14.5) which solves Navier-Stokes equation with Spalart-Allmaras one equation turbulent model. Second order discretization was used for flow variables and turbulent viscosity equation with Roe-FDS scheme. A comparison was performed for $\alpha=0^{\circ}$ with the available experimental data. These 3-D unsteady CFD investigations have provided fundamental understanding of flow field over an artillery projectile.

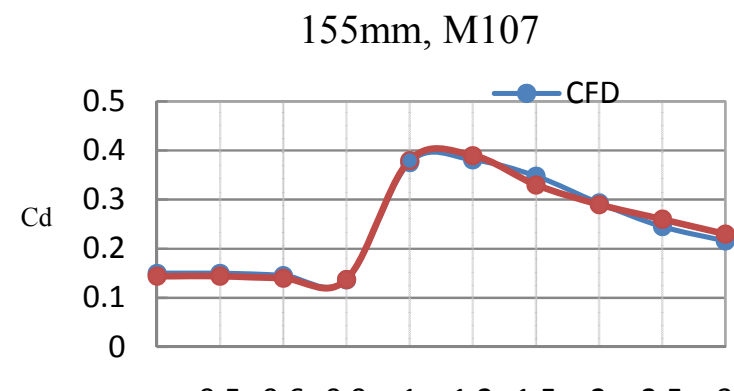

$\begin{array}{lllllllll}0.5 & 0.6 & 0.9 & 1 & 1.2 & 1.5 & 2 & 2.5 & 3\end{array}$

\section{Mach number}

FIGURE IX. COMPARISON BETWEEN CFD SIMULATION AND EXPERIMENTAL DRAG COEFFICIENTS FOR A $=0^{\circ}$

\section{ACKNOWLEDGEMENTS}

This work supported by the Foundation of Key Laboratory of Transient Physics (9140C300205110C30), China.

\section{REFERENCES}

[1] Sahu, J., 1991. Transonic Navier-Stokes computations for a spinning body of revolution. Tech.Rep. ARL-TR-3265, U.S. Army Research Laboratory. 
[2] Weinacht, P., 2003. Prediction of projectile performance, stability, and free-flight motion usingcomputational fluid dynamics. Tech. Rep. ARL-TR-3015, Army Research Laboratory.

[3] Robert L. McCoy, "Modern Exterior Ballistics", 4thedition, ISBN-0-7643-0720-7, Schiffir Publishing Ltd., 1998. 